\title{
SERUM LIPID PROFILE IN HYPOTHYROID PATIENTS IN NEPAL
}

\author{
Aryal $\mathrm{S}^{1}$, Joshi $\mathrm{A}^{2}$
}

\section{ABSTRACT}

INTRODUCTION: Hypothyroidism is non-curable common endocrine disorder in which the thyroid gland is unable to produce enough thyroid hormone. Present with a number of symptoms, Having a low level of thyroid hormone affects our whole body. Untreated hypothyroidism can be the cause of raised cholesterol levels. Many study have shown association between hypothyroidism and lipid profile. In this study, we evaluate the mean lipid profile status in subclinical hypothyroidism and hypothyroid patients.

MATERIAL AND METHODS: A hospital based retrospective study done from the record card maintained in Alka Hospital, Jawalakhel. Total number of participants were 215. Out of which 73 had overt hypothyroidism, 92 had subclinical hypothyroidism and 50 were taken as control. SPSS version 20 was used for data analysis.

RESULTS: The level of LDL, TG and TC was significantly higher in case of overt hypothyroidism as compared to control group, but no significant difference was found in subclinical hypothyroidism and control group. TG level was significantly lower in subclinical hypothyroidism cases.

CONCLUSION: Elevated HDL, LDL \& TC is seen in overt hypothyroid patients. It is important to screen for lipid profile in hypothyroid patients.

KEY WORDS: Hypothyroidism, Lipid profile, Subclinical hypothyroidism

1. Research officer, Alka Diabetes, Thyroid and Hormone Center, Alka hospital, Jawalakhel, Lalitpur, Nepal

2. Alka Diabetes, Thyroid and Hormone Center, Alka hospital, Jawalakhel, Lalitpur, Nepal

\author{
For Correspondence \\ Mr. Sudip Aryal \\ Research Officer, \\ Alka Diabetes, Thyroid and Hormone Center, \\ Alka hospital, Jawalakhel, Lalitpur, Nepal \\ E-mail: sudiparya1026@gmail.com
}




\section{INTRODUCTION}

Hypothyroidism is a common endocrinological disorder. It is a clinical state resulting from an insufficient amount of circulating thyroid hormone to support normal body function. ${ }^{1}$ It can start at any age, but is more common in older age group. In women, It often begins during pregnancy, which may leads to miscarriage and infertility too. It may begin after delivery, or around menopause. In children, Hypothyroidism may delay their growth and development. Some studies showed that, there was significant increase in the mean concentration of total cholesterol and triglyceride in case of hypothyroidism. ${ }^{2}$ Hypothyroidism appears to be associated with abnormalities in the serum cholesterol or triglyceride levels. There might be a potential link between hypothyroidism and cardiovascular diseases such as atherosclerosis. ${ }^{3}$ Some study showed that mean total cholesterol and mean LDL levels were significantly higher in subclinical hypothyroidism compared to their controls, but there was no statistically significant difference in the mean HDL, VLDL, and triglyceride levels. ${ }^{4}$ The main aim of our study is to evaluate the mean lipid profile status of people in subclinical hypothyroidism and overt hypothyroidism stage. One of the study, in patient with dyslipidemia, it showed that the Prevalence of overt hypothyroidism in patients with dyslipidemia is not low; $2.8 \%$ of the patients who were examined in outpatient lipid clinic had elevated levels of TSH and reduced levels of FT4. ${ }^{5}$

Although, there is a debate in treating the patient with subclinical hypothyroidism, many patient with subclinical hypothyroidism may develop to overt hypothyroidism. So, female, in pregnancy, after delivery, with mild increased TSH level should be in regular follow up with their TSH report.

\section{MATERIALAND METHODS}

Our study was a hospital based retrospective study in which the data were taken from the record card maintained in alka diabetes, thyroid and hormone center, Alka Hospital, Jawalakhel, Lalitpur, Nepal from March 2013 to March 2014. Out of 215 patients, 73 patients of overt hypothyroidism, 92 patients of subclinical hypothyroidism, and 50 patients of control groups were included in the study. Our variables for this study were age, sex, BMI, free T3, free T4, TSH, HDL, LDL, Triglyceride level, and Total cholesterol (TC).

Data were entered in Microsoft excel and statistical analyses were performed by using SPSS version 20. Mean value of findings were compared among overt hypothyroidism and
Subclinical hypothyroidism.

\section{Exclusion Criteria:}

Only the case with initial Thyroid Function Test (TFT) reports, free T3, free T4, TSH were taken for this study. i.e. cases without initial freeT3, freeT4 and TSH report were excluded from our study. Similarly, cases with Total t3, Total t4 were not taken for our study.

\section{RESULTS}

The demographic data of the patients in the study is shown in (Table 1).

Table 1: Demographic profile of study sample

\begin{tabular}{|l|ll|l|l|l|l|}
\hline & N & Male & Female & Age(yr.) & BMI & WT(kg) \\
\hline Subclinical Hypothyroidism & 92 & 29 & 63 & $43.5 \pm 10.93$ & $29.03 \pm 5.09$ & $70.84 \pm 14.16$ \\
\hline Overt Hypothyroidism & 73 & 24 & 49 & $44.9 \pm 13.24$ & $28.79 \pm 4.59$ & $70.38 \pm 11.03$ \\
\hline
\end{tabular}

The mean thyroid profile of patients of these two group subclinical hypothyroidism and overt hypothyroidism is shown in (Table 2).

Table 2: Thyroid profile of study sample

\begin{tabular}{|l|l|l|l|}
\hline & Ft3(2.3-4.2)pg./ml & Ft4(0.8-2)ng/dl & TSH(0.4-4.5) ul U/ml \\
\hline Overt Hypothyroidism & $2.29 \pm 0.98$ & $0.76 \pm 0.32$ & $28.80 \pm 44.91$ \\
\hline & & & \\
\hline Subclinical Hypothyroidism & $2.6 \pm 0.72$ & $1.28 \pm 1.69$ & $7.68 \pm 2.39$ \\
\hline
\end{tabular}

The patients with subclinical hypothyroidism have Ft3 and Ft4 within normal range and high TSH levels. While, the patients with overt hypothyroidism have low $\mathrm{Ft} 3$ and $\mathrm{Ft} 4$ and high $\mathrm{TSH}$ levels.

In this study data are presented as frequency and mean \pm SD for parametric value. T-test was performed to analyze data $\mathrm{p}<0.005$ is considered significant. Out of 73 hypothyroid patients 24 male and 49 female. Similarly, out of 92 subclinical patient 29 male and 63 female, whereas out of 50 control group 41 male and 9 female. There was a significant difference $(p=0.00)$ in sex between these hypothyroid and control groups. The mean LDL, TG and TC levels in the hypothyroid groups were significantly higher $(95.90 \pm 33.05$ to $115 \pm 36.70$, $\mathrm{p}=0.002^{*}, 134.16 \pm 44.83$ to $232.20 \pm 168.58, \mathrm{p}=0.00 *$ and $170.24 \pm 35.67$ to $232.20 \pm 168.58, \mathrm{p}=0.005^{*}$ ) respectively as compared to these in the control group and these value were higher than the reference value. Though, the LDL and TC level were higher in the subclinical group as compared to those in 
the control group ( $95.90 \pm 33.054$ to $97.76 \pm 32.32, \mathrm{p}=0.613$ and $170.24 \pm 35.67$ to $181.71 \pm 47.75, p=0.56$ ) respectively, but there was no significant difference seen. The TG level in the subclinical group were significantly lower134.16 \pm 44.83 to $178.64 \pm 104.902, \mathrm{p}=0.022$ ). (Table 3 )

Table 3: Comparison of mean lipid profile between normal and hypothyroidism and subclinical hypothyroidism

\begin{tabular}{|l|l|l|l|}
\hline Parameters & Overt Hypothyroidis m & $\begin{array}{l}\text { Subclinical } \\
\text { hypothyroi dism }\end{array}$ & Control \\
\hline LDL(mg/dl $)$ & $\begin{array}{l}115 \pm 36.70 \\
\mathrm{P}=0.002^{*}\end{array}$ & $\begin{array}{l}97.76 \pm 32.32 \\
\mathrm{P}=0.613\end{array}$ & $95.90 \pm 33.054$ \\
\hline $\mathrm{HDL}(\mathrm{mg} / \mathrm{dl})$ & $47.82 \pm 31.79$ & $46.24 \pm 14.79$ & $47.58 \pm 2.49$ \\
& $\mathrm{P}=0.771$ & $\mathrm{P}=0.589$ & \\
\hline $\mathrm{TG}(\mathrm{mg} / \mathrm{dl})$ & $232.20 \pm 168.58$ & $178.68 \pm 104.902$ & $134.16 \pm 44.83$ \\
& $\mathrm{P}=0.00^{*}$ & $\mathrm{P}=0.022$ & \\
\hline $\mathrm{TC}(\mathrm{mg} / \mathrm{dl})$ & $200.8 \pm 49.08$ & $181.71 \pm 47.75$ & $170.24 \pm 35.67$ \\
& $\mathrm{P}=0.005^{*}$ & $\mathrm{P}=0.560$ & \\
\hline
\end{tabular}

Pvalue $(*)$ indicates the significance of T-test

Although, the average BMI and average age were however comparable in both groups. In our study about $32.9 \%$ were male and $67.1 \%$ were female in overt hypothyroidism, while, $31.5 \%$ were male and $68.5 \%$ were female in subclinical hypothyroidism, which shows that female are more vulnerable than male for thyroid dysfunction and lipid dysfunction.

\section{DISCUSSION}

Hypothyroidism is a common metabolic disorder. The prevalence of primary hypothyroidism is $1: 100$, but it may be 5:100 if patients with subclinical hypothyroidism (normal T4, raised TSH) are included. ${ }^{6}$ The thyroid hormone influences the metabolism of cholesterol and the triglycerides. The degradation of cholesterol is caused due to an increase in the hepatic LDL and in the number of receptors and an accelerated LDL clearance. Consequently, the TC and LDL levels are elevated in patients with hypothyroidism. The increase in LDL results in a decreased conversion of cholesterol to the bile acids and the down-regulation of the LDL receptor. Increased levels of very low density lipoprotein (VLDL) and chylomicrons are present due to the decreased activity of lipoprotein lipase, resulting in a decreased clearance of triglyceride rich lipoprotein, thus reflecting the decreased activity of hepatic lipase. ${ }^{7}$ Hypothyroidism has been generally considered as a cardiovascular risk factor in a majority of studies, mainly because of its association with elevated serum total cholesterol and serum LDL. Our present study indicated that overt hypothyroidism was associated with an abnormal lipid profile with respect to triglyceride level. Hence, persons suffering from hypothyroidism should make life style and dietary adjustments to avoid future cardiovascular complications.

In older people who are free from the thyroid disease, the thyroid function remains relatively normal, because the thyroidal uptake of iodine is decreased. Hence, the daily production of $\mathrm{T} 3$ and $\mathrm{T} 4$ also decreases. This change appears to be concomitant with a decreased rate of T3 degradation. Thus, the overall concentrations of $\mathrm{T} 3$ and $\mathrm{T} 4$ do not appear to change with age. The TSH levels are lowered as age advances. But, the prevalence of the thyroidal disease increases with age. ${ }^{8}$ This study indicated that serum TSH level was elevated with decreased level of Ft3 and Ft4 in overt hypothyroidism with respect to moderate increased serum TSH within normal range of Ft 3 and $\mathrm{Ft} 4$ level in subclinical hypothyroidism.

Serum TC and serum triglyceride level was increased in the overt hypothyroidism as compared to the control group. Although there was not more elevation in HDL. This study found that the level of LDL was elevated in the overt hypothyroidism as compared to those in control group. Our study did not show the statistical significance difference in TC $(p=0.56)$ in compared to those of control group.

\section{CONCLUSION}

TC, TG and LDL levels are elevated in overt hypothyroidism with respect to subclinical hypothyroidism. Thyroid dysfunction can have an important effect on lipid profile. ${ }^{5}$ There have been studies suggesting that screening for thyroid dysfunction is cost effective.' From this study, it can be concluded that hypothyroidism is common in middle aged women as shown in (Table no 1). Untreated hypothyroidism (overt $>$ subclinical) can be related to coronary artery disease. So, in Nepal early screening of hypothyroidism is needed in women after the age of $40 \mathrm{yrs}$., in pregnancy and after delivery, and in women and men with dyslipidemia in order to challenge the problem of untreated cases of hypothyroidism. Close monitoring of thyroid function test could be the best option for hypothyroid patients at high risk group.

\section{REFERENCES}

1. Paudel BPK, Upadhaya TL. Clinical Manifestations in hypothyroidism in western region of Nepal: A case control study. Nepal Journal of medical science. 2013;2(1):62-5.

2. Mittal A SB, Kumar A, Chandrasekharan N, Dwedi S. The Clinical Implications of Thyroid Hormones and its Association with Lipid Profile: A Comparative Study from Western Nepal. Nepal Journal of Epidemiology 2010;1(1):11-6. http:// dx. doi. 
org/10.3126/nje.v1i1.4102

3. Mondal SI DS, Akther A, Hasan R, Talukdar SA, Reza MDS. Thyroid Hormone and Its Correlation with Age, Sexand Serum Lipid Levels in Hypothyroid andEuthyroidSylheti Populations in Bangladesh. Journal of Clinical and Diagnostic Research. 2011 November (Suppl-2); Vol-5(7):1347-51.

4. Asranna A TR, Kulshreshta B. Dyslipidemia in subclinical hypothyroidism and the effect of thyroxine on lipid profile. Indian JEndocrinol Metab. 2012 Dec;16(Suppl 2):347-9.

5. Liberopoulos EN EM. Dyslipidemia in patients with thyroid disorders. Hormones (Athens). 2002 Oct-Dec; 1(4):218-23. http://dx.doi.org/10.14310/horm.2002.1170

6. Walker BR TAIHC, Chilvers ER BN, Colledge NR (Eds). London: Churchill Livingstone. Endocrine disease. Davidson's principles and practice of medicine 2002; 19th edn: 683-746.

7. RAVI SHEKHAR SCH, M.C. DAS. Lipid Profile in 'Newly Diagnosed' and 'On Treatment' Hypothyroid. Journal of Clinical and Diagnostic Research. 2011 October; Vol-5(5): 998-1000.

8. Isabela MB AC, Paulo AL, Paulo RM, Marcia S. Prevalence of thyroid disorders among older people: results from the Sao Paulo
Ageing and Health Study. . Cad Saude Publica. 2011; 27: 155-61. http://dx.doi.org/10.1590/S0102-311X2011000100016 http://dx.doi.org/10.1590/S0102-311X2011001400004

9. Danese MD PN, Sawin CT, Ladenson PW. Screening formild thyroid failure at the periodic health examination: a decisionand cost-effectiveness analysis. JAMA. 1996; 276:85-92. http://dx.doi.org/10.1001/jama.276.4.285 http://dx.doi.org/10.1001/jama.1996.03540040029029 http://dx.doi.org/10.1001/jama.276.2.85 